\title{
Probiotic as Immune Modulator; A New Trend in Medication
}

\author{
Zahed Mahmood $^{1}$, Muazzama Zahid ${ }^{1}$, Muhammad Jahangeer ${ }^{1 *}$, Areej Riasat ${ }^{1}$, \\ Naveed Munir ${ }^{1,2}$, Muhammad Asad ${ }^{1}$ \\ ${ }^{1}$ Department of Biochemistry Government College University Faisalabad, 38000. \\ * rajahangeer@gcuf.edu.pk \\ ${ }^{2}$ Department of Allied Health Professionals, Government College University Faisalabad, 38000.
}

\begin{abstract}
:
Probiotics are live microbes that confer beneficial health effects to the host when administered in sufficient amount. The dead bacteria may express the properties of probiotic components. The most common strains of probiotics are lactobacillus and Bifidobacterium, these are also present in functional food stuffs mostly in dairy and fermented foods. The use of probiotics based on the goal of producing food microbes that are healthy for intestine and food ingestion. Basically, the purpose of probiotics is to prevent from pathogens and maintain the proper gastrointestinal functions. The probiotics ameliorate many digestive disorders included, lactose intolerance, irritable bowel syndrome and antibiotic associated diarrhea. Probiotics also treat other diseases such as cardiovascular diseases, diabetes, obesity, liver diseases, cancer and in the treatment of HIV. The patients of HIV who are on antiretroviral therapy, they, may have dysbiosis of gut microbiom. The probiotics are useful for the prevention of immunological activity of gut. Probiotics have different mechanism of action such as colonization of perturbed microbes in intestine, pathogens exclusion competitively, mucin production cell adhesion, production of short chain fatty acids and immune system modulation mainly differentiate the $T$ regs and increase the regulation of antiinflammatory cytokines (IL-10) and growth factors.
\end{abstract}

Keywords: Probiotics, lactobacillus, Bifidobacterium, microbiom, cytokines, HIV.

\section{Introduction}

"Let the food be your medicine and medicine be your food" said by Hippocrates in IV century. In 1907 Eli Metchnikoff was first who proposed the beneficial effect of bacteria in our gastrointestinal tract. He give his "Theory of longevity "in which he associate the prolong life of Bulgarians with the consumption of "sour milk" (Kaufmann 2008). Since after that research continues to understand the role of nutrients in health improvement or in the prevention of diseases. The research has been shown that a large number of foods have distinct beneficial effects and these foods are then termed "functional foods". These functional foods not only play role in the enhancement of health but also very useful in improving many physiological functions of the body and for the treatment of different diseases. They fulfill the body requirement of certain vitamins, carbohydrates, proteins and fats (Cencic \& Chingwaru 2010). The use of prebiotics ( pre "before" bios "life") a substance that is undigestable and help in promoting the growth of beneficial bacteria, probiotics ( pro" forward" bios "life") it is a substance containing 
beneficial micro organisms for host and symbiotic ( sym "plus" bios" life") composed of both probiotics and prebiotics. Basically these three have the same role, production of that food stuff which provide healthy microbes in the intestine by ingestion and it can be achieved either by probiotics ( healthy microbes addition) and prebiotics ( such as undigestable polysaccharide). Thus ,the definition of functional foods " addition of ingredients in food components that help in promoting health (Bottazzi, 1983).

The oldest known functional food is sour milk (fermented milk) now a day's known as yogurt, has been known to consumed for over 1000's years and found to be effective in GI problems. Basically the purpose of probiotics is to prevent from pathogens, improve immune response in case of infections, and maintain the functions of GI. Prebiotics are that components of food which help in promoting growth of microbes and persistence of beneficial bacteria ingested at the same time (Ahmed et al., 2013). Recently the probiotic term refers to the soluble components having biological activity, to be an alternative in using whole bacteria, safely (Tsilingiri et al., 2012). The probiotics effects have been previously reported such as prevention from diseases, including diarrhea due to antibiotics (Hempel et al., 2012), inflammatory bowel disease (Saez-Lara et al., 2015) and many other problems of gastrointestine.

Even that many strains of probiotics are found to be safe in many published documents, the FDA and ESFA the European Food Safety Authority has not attribute and approved any product of probiotics in health claims associate with the administration of probiotics. Over 300 requests for approval of 200 probiotics strains and their combinations have been submitted with a clame of more than $60 \%$ beneficial. The reasons behind in these requests for denied probiotics approval were: insufficient characterization, non beneficent and undefended claims, insufficiency in related human studies and outcomes and the quality of present study (Salminen, 2017).

Nevertheless, a multi-strain probiotic [L.helveticus (SD5210)], thermophilus (SD5207), L.plantarum(SD5209), B.breve (SD5206), B.animalissub sp. lactis (SD5220, SD5219), L. paracasei (SD5218), L.acidophilus (SD5212), and S. salivarius have been approved by the health Canada and also a single strain for IBS symptomatic treatment as lactis LAFTI B94 and B. animals (Plaza-Diaz et al., 2019).

Probiotics alter the intestinal microbial diversity and thus perturbed the microbes of intestine in many specific modes of action and these mechanisms have not been fully elucidated. In this literature the varied modes of probiotic action have been illustrated to understand their role in the maintenance of host metabolism. There are different mechanism such as 1) pathogen exclusion in a competitive way and production of bacteriocins 2) normalization and colonization of microbes in intestine of children as well as in adults, 3) SCFA production and enzymatic activity, 4) cell adhesion to intestinal epithelium, 5) Interaction of probiotics with brain gut (Mendes et al., 2018).

The probiotics known to be effective in many diseases similarly in an immune system disease, HIV a virus that infect our immune system and kills the CD 4 cells. In the initial stage of HIV the infection occurs in the immune system of gut contain $2 / 3^{\text {rd }}$ of CD 4 cellls. Th 17 cells protect the gastrointestinal integrity by microbial translocation. The microorganisms present in our gut play an effective role in the progress and also the pathogenesis of HIV. Research is going on probiotics that are helpful in HIV lowering infection. For enhancing the gut microbiota life span the probiotics are used (Nowak et al., 2015). 


\section{The Concept of Probiotics}

Probiotics are defined according to a definition recently from Germany such as "Live microbes which can reach the intestine of the host in active form. Probiotics termed was first coined in 1950 by Kollath and was first used by Lilly and Stillwell in 1965. Fuller in 1989 firstly give the accepted definition of probiotics, "These are live microbes that can affect beneficially on human health through improvement of intestinal balance". Carre in 1887 present the idea of pathogens growth suppression by orally administered probiotics. Probiotics further defined by WHO in 2001 as "live microorganisms that when administrated in adequate amounts confer health benefit effects on the host."

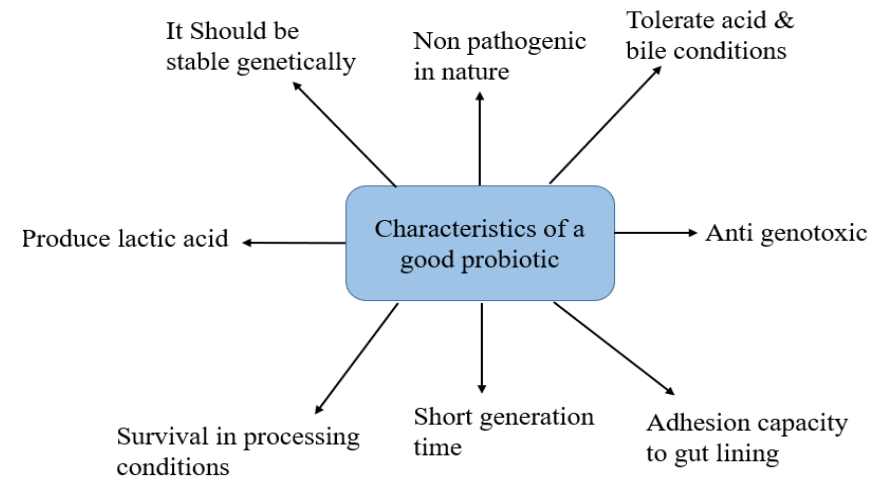

Figure.1. General Characteristics of a Good Probiotic

Taxonomy of Probiotic Microorganisms; Different species of bacteria and yeast have been proposed to utilize as probiotic but commonly known are the Lactobacillus \& Bifdobacterium. Both of these are known to be gram positive containing thick peptidoglycan layer and having capability of producing lactic acid. These bacteria composed on the major portion of microbial intestine (Fujiya et al., 2014).

Table .1: Probiotic microorganisms

\begin{tabular}{lll}
\multicolumn{1}{c}{ Lactobacilli } & \multicolumn{1}{c}{ Bifdobacteria } & Others \\
\hline L. sanfranciscensis & B. pseudolongumgroup & S. thermophilus \\
L. kefri & B. asteroids group & Lactococcus lactis \\
L. kefri & B. pullorum group & Enterococcus faecalis \\
L. panis & B. boumgroup & Propionibacteria \\
L. delbrueckiisubsp. lactis & B. adolescentisgroup & S. boulardii \\
\hline
\end{tabular}




\section{Modes of Probiotics Action} Normalization and colonization of microbes in intestine of children as well as in adults Children; Colonization of GI tract seems in early stage in infants determine the establishment of gut microbiota later in life (Yang et al., 2016). Before the birth of a child the assembly of intestinal microbiome starts which continues to infancy. Different factors influence the microbiome colonization in the initial stage such as utilization of antibiotics, method of birth, newborn genetic organization, feeding, inflammatory conditions of mother (Hesla et al., 2014). Some type of bacteria such as isolated from the blood of umbilical cord and placenta (Staphylococcus epidermidis, Enterococcus faecium, Escherichia coli and Propionibacterium acnes) also affect the colonization of intestinal microbiome (Aagaard et al., 2014). On the other hand the bacteria found in vagina and milk of mother are likely to be important for colonization of gut microbiota (Murphy et al., 2017). Bacterial adhesion on the surface of host is a critical aspect in the colonization which is important and preventive in clearance of pathogens.

There are a wide range of structures on the surfaces of bacteria that are known to have adhesion properties. In addition the hair like polymeric organelles known as pili that are present on the bacterial surface are important structure as they firstly involved in bacterial binding to the host cells. Due to adhesive nature of bacterial surface, they are able to recognize the host cell molecules as cadherins, proteins of trans membrane, extracellular matrix components, integrins, elastin and fibronectin (Ribet \& Cossart, 2015). The preclinical studies in children that uses probiotics represent positive results regarding the normalization of microbiome, decline in pathogenic infection, responsive immune system improvement and maturation of intestine and some studies also show changes in microbiome composition of intestine (Szajewska, 2016). In case of children the clinical studies show the administration of specific probiotics are important in reducing the severity of several pathological conditions such as diarrhea associated with antibiotics consumption, allergies, necrotizing enterocolitis, colic and irritable bowel syndrome (Hojsak et al., 2018).

The evidence indicate the use of probiotic Lactobacillus reuteri help to improve the crying spells, only after the treatment of two to three weaks, even if the disorder is naturally present (Xu et al., 2015). Many other strains of Bifidobacteria shown to be effective beneficially in the alleviation of colic infant symptoms that involve the changes in perturbed intestinal microbiota composition. There is an increase in the abundance of Bifidobacteria with the consumption of Lactobacillus rhamnosus GG as compared to placebo consumption. For the prevention of different types o diarrhea, in respect to consumption of probiotics they act as preventive by restoring the balance of perturbed microbiota and also as treatment to inhibit the pathogens proliferation such as $C$. difficile (Pärtty et al., 2015).

Use of probiotics in adult diseases; The colonization starts as soon after the probiotic administration. Some of the studies have documented this step while others have described the outcomes of association in those results and administration of microbes. In a healthy adult the probiotic causes an increase in SCFAs production, fecal moisture and defecation frequency (Olivares et al., 2006). The symptoms of gastrointestinal such as consistency of stool and frequency of defecation were not influenced by a probiotic $L$. rhamnosusPRSFL477. It indicate that it is a tolerated bacterium. Therefore the presence of L.rhamnosuswas an issue in the subject feces (Wind et al., 2010). The bacterium 
Lactobacillus salivariusCECT5713 known to have tolerance in adults of healthy people was assessed. This strain shown to be tolerated and have no undesirable effects but there was not any attempt in case of the evaluation of colonization with this strain (Sierra et al., 2010).

However, in volunteers of receiving $L$. rhamnosus CNCM I-4036 strain the persistence in their intestine was observed byt using a detection method of qRT PCR primers (Plaza-Diaz et al., 2013). The probiotic effect in the people go ahead of their health status as the obese and overweight persons are best candidates who should receive probiotics, as individual strain treatment and also the multistrain probiotics. VSL\#3 is prepared by multi strains of probiotics and has been tested in obese and overweight subjects. Administration of VSL\#3 is also very useful in a treatment of reducing the lipids concentrations and $\mathrm{C}$ - reactive protein highly sensitive inflammatory markers, increase the sensitivity of insulin and also produce gut microbiota changes (Rajkumar et al., 2014). The patients of overweight, hypertention can decreased their blood pressure and BMI by consuming L. plantarum TENSIA (Sharafedtinov et al., 2013).

There are some strains of bacteria that produce butyrate such as (B. pullicaecorum 253T, F . prausnitzii, B. pullicaecorum 1.20 and a mixture of $B$. pullicaecorum 25-3T, $F$. prausnitzii, Eubacterium hallii, Anaerostipes caccae and Roseburia hominis ) were evaluated in crohn disease to stimulate mucus production. All of the strains assays exhibit increase in the production of butyrate and they also involve in improving epithelial barrier integrity (Geirnaert et al., 2017). There is possibility of alterations in the microbiota of gut with the progression of irritable bowel disease. The treatment results with probiotics in the patients of Crohn disease CD shown to be no remission: on the other hand consumption of probiotics in ulcerative colitis patients showed effectiveness in pathology remission, specifically with the treatment of VSL \#3 and through the combination of prebiotics and Lactobacillus (Ganji-Arjenaki et al., 2018).

Pathogen exclusion in a competitive way and production of bacteriocins; The competitively excluding microorganisms (pathogens) refers to the competition among bacterial species for binding to receptor site in GI tract (Bermudez-Brito et al., 2012).The specific pathways underlie key regulatory methods of probiotic effects are mostly unknown. Nutritional source competition, reduction of luminal $\mathrm{pH}$, and bacteriocin production and substances like bacteriocin are the main mechanisms of pathogen exclusion competitively (Collado et al., 2010).Many of the studies regarding the reduction in pathogens focus on E. coli and Salmonella typhi decrease (Munoz-Quezada et al., 2013). However, some metabolites of probiotics appear to have a role in modulating metabolic pathways and diverse signaling. The metablome components (bacteriocins, hydrogen peroxide and organic acids) of probiotics have been documented to interact multiple targets within certain metabolic pathways involving regulation of cell proliferation, apoptosis, angiogenesis, inflammation, differentiation and metastasis (Kumar et al., 2013).

Some of lactobacilli species and bifidobacteria capable to produce bacteriocins which are anti microbial peptides that help to prevent the pathogens proliferation. The utilization of probiotics for treatment and prevention of pathogens is termed as "colonization resistance" (Bermudez-Brito et al., 2012). The bacteriocins are of 30-60 amino acid residues and of cationic nature. The function of these bacteriocins is to act on the cytoplamic membrane of bacteria and causes the disruption of proton motive force by 
targeting the membrane vesicles (Mokoena et al., 2017). The classification of bacteriocins based on molecular mass, genetic constitution, primary structures and post translational modifications, in this respect they are of 4 types (Mokoena et al., 2017). Specifically some of bacteriocins produced by L. acidophilus and L. plantarum shown to have inhibitory effect on the growth of C. difcile, H.pylori, Shigella (a multi drug resistant) and rotavirus in GI tract problems. They also exhibit activity to inhibit uropathogens (Kumar et al., 2016).

\section{Enzymatic Activities and Production of Volatile Fatty Acids Enzymatic Activities}

The interaction of probiotics in the gut with bile acids causes the modification of metabolism of bile acid and also influence the absorption of cholesterol. The enzyme hydrolase of bile salt is produced by several bacteria and also by commonly known probiotics, this enzyme is associated with GI tract. The function of this enzyme is to participate in the deconjugation, the first step in bile salt metabolism. Due to the consideration of these bile salt hydrolase efficacy, this enzyme has been known to included under the guidelines of WHO for evaluating the use of probiotics food. The process of deconjugation by bile salt hydrolase considered to have the main functioning in the hypocholesterolemic attributed by probiotics (Kumar et al., 2011).There was also seen reduction in amino traneferase level in liver in the non alcoholic treatment of fatty liver in some adult patients, it was well documented by testing probiotics in a systemic RCT (Buss et al., 2014). Another RCT in which 30 healthy adults included for the evaluation of effect in a fermented product of two different strains of bacteria Lactobacillus coryniformis CECT5711 and Lactobacillus gasseri CECT5714 on host intestine in comparison of standard yogurt, there were enzymatic activity of 19 types detected in feces of subjects.

The activity of enzymes exhibited by a group treated by probiotics and that of control group shown to be stable throughout the study. Though, the activity of naphthol-AS-BIphosphate by lactobacilli seen to improved in the probiotic treatment. Additionally, the enzymatic activity of leucine arylamidase characterized by several strains of probiotics also increased on the other hand the activity of beta-D-glucuronidase was reduced. The probiotics interact with bile acids in the lumen thus modifying the metabolism of bile acid which in turn may influence the cholesterol absorption (Olivares et al., 2006).

Production of volatile fatty acids; The RCT of 33 healthy persons of different ages, young, elderly and middle age. They were given an oral dose on daily basis composed of L. plantarum Lp-8. Both the propionate and acetic acid concentration increases and butyrate not increase, under the 5 week period. When the consumption of Lp-8 was terminated, both the concentration of propionate and acetate was decreases slowly but it was higher from the concentration of baseline (Wang et al., 2014). It is cleared that the butyrate production is dependent on Specific type of probiotics used.

The probiotics effect on NAFLD, obesity, syndrome of insulin resistance and T2D. The patients of BMI show beneficial effects with the use of symbiotics and probiotics. The probiotics also show effectiveness for insulin resistance and decrease the level of cardiovascular disease biomarkers. Further, the probiotics which are selected also help to 


\section{Frontiers in Chemical Sciences (FCS)}

improve the glucose level of blood in fasting, antioxidant levels, metabolism of carbohydrates and people with T2D reduce their metabolic stress. The selected probiotics may also beneficial for improving the metabolic markers of liver and NAFLD (Sáez-Lara et al., 2016). Evidence from another RCT revealed that L.salivarius-33 show effectiveness on obese adolescents. During the period of over 12 weeks, the group of bacteroids ratio, such as Eubacteria rectale, Clostridium cluster XIV, R. Intestinal is and Blautia coccoides increases when Ls-33 was administered. Nevertheless there were no alteration in bifidobacterium and lactobacillus by this intervention same as the concentration of SCFA was also unaffected (Larsen et al., 2013).

The SCFA have been show several biochemical, molecular and physiological effects on different body tissues such as brain, liver tissues, muscular tissues and fat deposited adipose tissues. SCFAs also known as important energy source for the intestinal cells. They also play an important role in the signaling mechanism of gut maintenance. SCFAs have ability to interact with the peripheral tissues receptor by entering in the blood systemic circulation. Though SCFAs play a significant role to regulate the metabolism and homeostasis of energy. The evidence of that show the increasing effects of SCFAs for the obesity associated disorders have been derived from the in vitro studies of animals, suggesting the SCFAs role in insulin resistance and glucose metabolism (Canfora et al., 2015). The SCFAs have been known to interact with its specific receptors, the GPR 41 (G protein coupled receptors) and GPR 43. Through this interaction SCFAs lead an important role in increasing the secretion of a peptide 1 like glucagon and intestinal polypeptide, that on the other hand involve to enhance the satiety (Hur \& Lee, 2015).

Additionally the role of SCFAs through interaction with its specific receptor GPR3 may contribute in decreasing the accumulated fat in adipose tissues. It results in the increased leptin released and adipogenesis and decrease the inflammation and lipolysis. Propionate affect the angiopoietin 4, inhibitor of lipoprotein lipase and increase the uptake of fatty acids. Another role of SCFAs by interacting with GPR43 may also reduce the intracellular lipolysis by decreasing the lipase phosphorylation. Same as, the propionate, butyrate and acetate mediate the adipogenesis by increasing the PPAR- $\gamma$ receptor which in turn is regulated by the SCFAs receptor GPR43 mechanism. Additionally the propionate, butyrate and acetate might reduce the cytokines, chemokines secretion by reducing the macrophage infiltration. SCFAs also activate the APM kinase of muscles cells by decreasing the accumulation of lipid and increasing the oxidation of fatty acids (Canfora et al., 2015). Other SCFAs biological activities attributed by probiotics results in epigenetic alterations that might explain the effects of anti carcinogenic through probiotics (Plaza-Diaz et al., 2019). Though the study in humans area is needed particularly. 
Mahmood et al.,

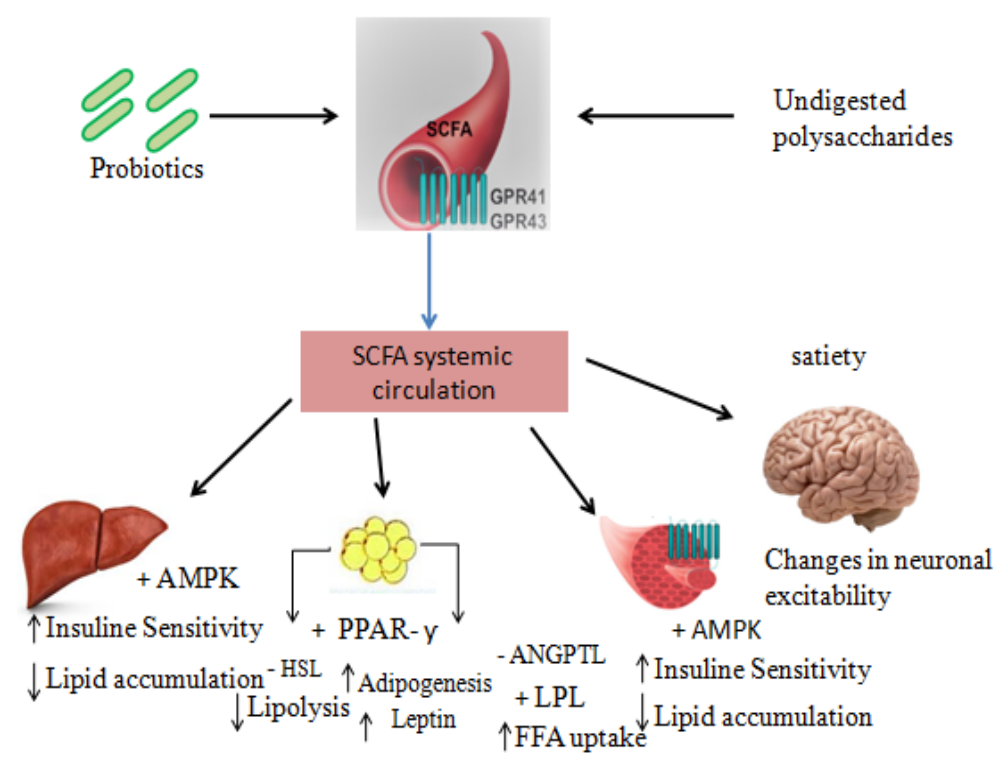

Figure 2. Enzymatic Activity and Volatile Fatty Acids Production

Production of mucin and cell adhesion; The microbial strain is designated to a probiotic, there is a need of specific requirements to be documented. The one is the adhesion on mucosal cell lining of the intestine for interaction between the different probiotic strains that are administered and host, and specifically for colonization (Bermudez-Brito et al., 2012). This specific type of interaction in very useful for antagonism modulation against the pathogens and for immune system function (Plaza-Díaz et al., 2018). The cells of intestinal epithelium secrete mucin and avoid adhesion of bacterial pathogens (Collado et al., 2010). Various strains of Lactobacillus bacteria have been known to stimulate this adhesion (Van Tassell et al., 2011), the L. rhamnosusstrain ATCC 7469 have been tested experimentally in F4 expressing strain of E.coli in the epithelium cells of porcrine J2. The TLR 4 and oligomerization binding nucleotide domain containing NOD 2 protein was improved in E.coli presence, and this augmentation was attenuated by treatment of L. rhamnosus.

The L. rhamnosustreatment increases the phosphorylation of Akt and also increases the expression of occludin protein and zonula occludends 1. The probiotics help in the maintenance of intestinal epithelial barrier by promoting activation of epithelial cell in response to pathogens (Zhang et al., 2015).Another study on L. plantarum evaluated its effect on intestinal barriers, in vivo, and transcription of mucosal gene in humans. The strain TIFN 101 of L. plantarum modulate the transcription pathway of genes, this probiotic causes the upregulation of metalloproteinase 2, muc 2 genes and metalloproteinase 1 tissue inhibitors and down regulation of the TCA II genes (Mujagic et al., 2017). 


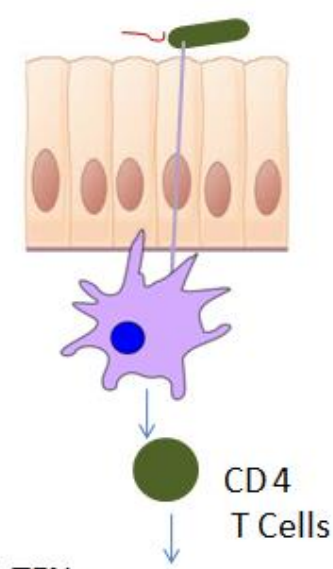

TFN- $\alpha$ IFN- $y$<smiles>[CH]1[CH]C1</smiles>

IL-10 TGF- 6

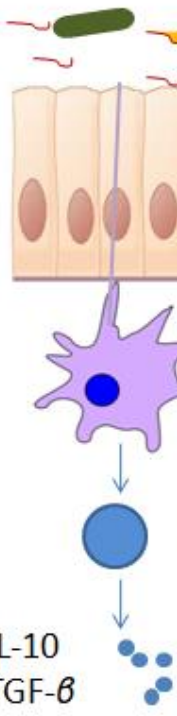

No Inflammation

Fox P3

T-reg
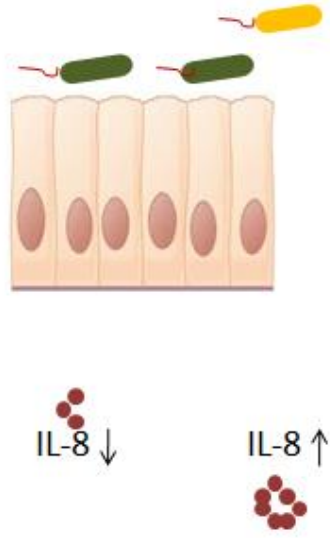

Probiotics

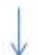

$\uparrow$ Gene expression

Figure 3. Cell Adhesion and Production of Mucin

Immune system modulation; The microbiom of gut modulate the immune functions through the production of anti inflammatory and immune system modulating molecules having capacity of immune system stimulation. This modulatory effect of immune system is due to the probiotics interaction with the epithelial cells and dendritic cells with lymphocytes and macrophages (D'Amelio\& Sassi, 2018). The major mechanism of probiotics action are regulating the immune responses of host. There are two types of immune system, the innate system and adaptive. The adaptive response mainly depends on $\mathrm{T}$ and $\mathrm{B}$ lymphocytes by binding to their specific type of antigens. The innate immune system responds to the PAMPs pathogen associated molecular patterns that are common to many of the pathogens. The most important response for pathogenic bacteria produced by PRRs pattern recognition receptors that can bind with PAMPs. As a consequence, the PRRs composed of TLRs, the trans membrane proteins present on different types of cells both immune system cells and nonimmune, such as the NK cells, dendritic cells, B cells, fibroblat and epithelial cells. Additionally, the PRRs composed of the oligomerization domain of nucleotide binding, lectins and adhesive molecules (Gómez-Llorente et al., 2010).

The Toll like receptors and PRRs including the NODLRs guard the space of cytoplasm (Claes et al., 2015). Other types of PRRs such as lectin receptors, retinoic acid like helicase, peptide receptors and IL1 activating factor of protease (Hevia et al., 2015). Generally, the $\mathrm{T}$ subset cells that are involve in immune balance regulation is tuned via microbes by which host interact and host itself. Thus, the dis equilibrium among the $\mathrm{T}$ 
regulatory cells and helper T cells leads to an impairement of immune system (Yousefi et al., 2015). The probiotics help in maintenance of host intestinal homeostasis by developing $\mathrm{T}$ regulatory cells and immune system modulation (Giorgetti et al., 2015).

Cytokine production and SIgA modulation.

The B cells of intestine secreted the sIgA and it is expressed on basolateral surface of epithelium, shown as transporter of antibody. The sIgA also assists in the $\operatorname{IgA}$ dimers translocation on the epithelium surfaces. Various studies on probiotics have been reported to show the stimulation of $\operatorname{sIgA}$ production and therefore, increases the barrier functions ((Wang et al., 2016). Nevertheless, the probiotic interaction with immune cells and specific intestinal cells results in cytokines production. The consumption of L. salivarius improved the NK cells or that of monocytes percentage and the concentration of plasma immunoglobulin A,G and M, also the IL-10 in adults (Sierra et al., 2010). The L. casei Shirota shown to increase the CD 69 expression of NK and T cells, the activation marker of circulating cells, and also increase the IgA2, IFN- $\gamma$ and IgA1 concentrations in adults (Harbige et al., 2016).

The administration of B. breve CNCM results in the significant increase of sIgA contens in fecal; the concentrations of IL-10 and IL-4 increases while the IL-2 decreases in the plasma. The same results were obtain in the treatment of two different probiotics L. caseiand L. rhamnosus in the serum of adult volunteers (Plaza-Diaz et al., 2013). Recently, E. faecium AL41 a probiotic was proposed to effective against infections of Campylobacter jejuniin the chickens. The E. faecium causes the modulation of TGF- $\beta 4$ and down regulate the IL-17 expression and activates the cells of IgA production in an infection of C. jejuniin chicks caeca ((Letnická et al., 2017). The trearment with L. rhamnosus RC007 in mice for 10 days enhances the macrophages phagocytic activity and the IgA cells of lamina in small intestine also increases. The oher results are the higher concentration of MCP-1, TNF- $\alpha$ and IL-10 were seen and the pro and anti-inflammatory (IL-10/TNF- $\alpha$ ) cytokines in the fluid of intestinal cells increases with the administration of L. rhamnosus (Dogi et al., 2016). Another strain of Lactobacillus (L. plantarum $06 \mathrm{CC} 2$ ) shown to have capability of increasing IL-2 concentration in the co culture of cells (J774.1). The production of cytokine Th1 was induced by oral administration, thus activating the Th1 response related to the immunity of intestine in mice (Takeda et al., 2013). The investigations are made on the ability of L. caseidifferent types to check their ability in the gut microbiota alteration. In this study it was seen that L. caseihave the ability of modulation in gut microbiota and immune system of the host. It is because the strains have relation in their ability to alter the different composition of PRR regulation, regulation of antimicrobial peptide and gut microbiota (Aktas et al., 2016). There are a number of species of probiotics, Bifidobacteria and lactobacilli, that have been proved to certain properties such as anti-inflammatory and pro-inflammatory by increasing Th1 and IL-10 cytokines concentrations.

A mixture of probiotics was identified to upregulates the CD4+ T regulatory cells+ FoxP3. The administration of a mixture of probiotics induced the hypo responsiveness of $\mathrm{B}$ and $\mathrm{T}$ cells and thus down regulated the different cytokines Th1, cytokine Th2 and Th17 without the induction of apoptosis. The mixture of probiotic also induced the CD4+ $\mathrm{T}$ regulatory cells + FoxP3 production from population of $\mathrm{CD} 4+\mathrm{CD} 25-$ and also increase 


\section{Frontiers in Chemical Sciences (FCS)}

the activity of CD4+T regulatory cells+CD25 whose activity was suppressed. The T cells conversion into fork head box P3 and T-regs is mediated by the regulation of DCs that is shown to have the high concentrations of TGF- $\beta$, indole amine, cyclooxygenase, 2,3 dioxygenase and interleukin 10. The mixture of probiotic had shown the therapeutic effects in the IBD treatment, rheumatoid arthritis and eczema. In general, the probiotic administration that help in enhancing the DCs regulation and $\mathrm{T}$ regulatory cells generation represented as an appropriate treatment of the immune system inflammation (Kwon et al., 2010).

Interaction of probiotics with TLRs and cell cascade signaling; TLRs are evolutionary family of receptors related to PRRs that have the ability of recognition to wide range of microbes. In mammals, there are 11 proteins included in the TLR family. These receptors activated by the ligand binding to the leucine rich extracellular repeats. The toll like receptors in humans that are associated with the membrane on outer layer are the TLR1, TLR2, TLR4, TLR5, TLR6 and TLR 10, there primary response is to the PAMPs associated to the bacterial surfaces. The other types of TLRs such as TLR3, TLR7, TLR8 and TLR9 are mostly present in the endosomes. There are primarily responds to the PAMPs based on nucleic acids from bacteria and viruses. The TLR pathway of signaling involves the MYD88 recruitment, that further activates the NF- $\kappa \mathrm{B}$ and MAPK signaling. The TLR3, with an exception of mechanism involves the utilization of TRIF an adaptor protein, that leads to the expression of interferons type 1. This type of signaling has been shown to control the DC maturation (Gómez-Llorente et al., 2010).

TLR9, a type of TLRs, can be activated by different probiotics. The in vivo studies shows that the TLR9 have anti-inflammatory effect on the surface of epithelium. Therefore, TLR9 when activates it induces the intracellular signaling mechanism through the basolateral and apical surfaces. In this way the NF- $\kappa \mathrm{B}$ is expressed by TNF- $\alpha-$ induction. As a result, the capability of probiotics to stimulate TLR9 is shown to be different. The TLR9 involves in the activation of NF- $\kappa$ B pathway and degradation of I $\kappa \mathrm{B} \alpha$. Whereas the TLR9 present on apical surface induces the ubiquitinated $\mathrm{I} \kappa \mathrm{B}$ accumulation and $\mathrm{NF}-\mathrm{kb}$ inhibition in the cytoplasm (Bermudez-Brito et al., 2012).

The probiotics have capability of suppressing inflammation in the intestine by down regulating the expression of TLR, metabolites secretion that can inhibit the entering of TNF-ain the blood cells, also causes the NF- $\kappa \mathrm{B}$ signaling inhibition in the enterocytes (Wells, 2011). The probiotic B. bifidum stimulates the expression of TLR2 in the epithelium of ileal and increases the expression of COX-2. It also enhances the prostaglandin E2 production in rats. The specific mechanism is not fully evaluated (Kailova et al., 2010). Certainly, the different strains of probiotics like L. plantarum CCFM734, L. acidophilus CCFM137, S. thermophilus CCFM218 and L. fermentum CCFM381 involve in the stimulation of TLR2 and TLR6 and the interactions between TLRs and PRRs are known to be strain specific. Therefore, in the signaling pathway of immune regulation the TL2 and TLR6 are essential receptors (Ren et al., 2016).

In a recent study involving transplantation of human gut microbiota to the pigs through several dosages of L. rhamnosus GG have been shown to affect the bacteria found in intestine and immune signaling modulation through orally attenuated the rotavirus vaccine of humans. The author describes the 9 doses treatment instead of 14 doses with L. rhamnosus GG and the results show the enhanced levels of TLR9 mRNA, IL-10, TNF- 
$\alpha$ and IL-10, the MAPK and kinase expression in ileal cells. Hence, the 9 doses show more effectiveness in the pathway of TLR9 signaling (Wang et al., 2016).

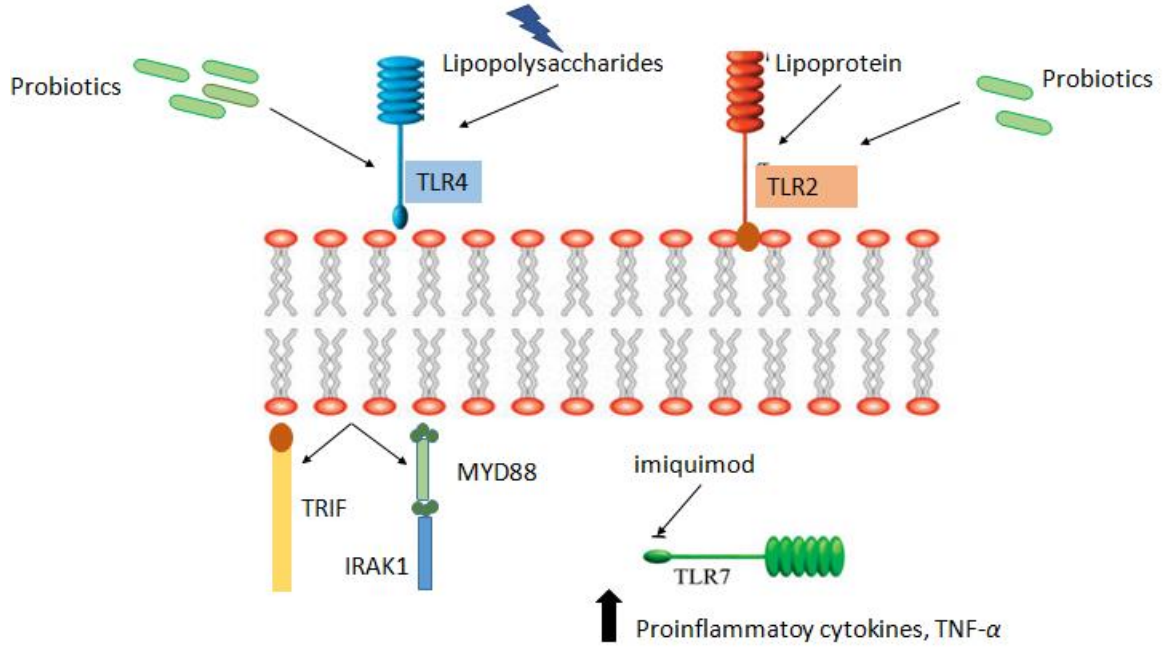

Figure 4. immune System Modulation

Interaction with the brain-gut axis; In the social environment, peoples who physically interact with each other in their social grooming possess more similarity in their gut bacteria (Tung et al., 2015). From this point of view the social interaction can elaborate the variations among the bacterial community of gut microbiota even they have controlled diet, shared environment and genetics of host. The degree of social transmission among the bacteria prove beneficial for their proliferation among themselves, some of the evidences suggests transmission of socially interactable microbiota may have beneficial effects on their host (Vuong et al., 2017). The signaling system in brain, microbiome of the intestine, and interaction among genetic receptors with microbiota have been associated with children health and also the behavior development of long and short term (Tillisch et al., 2013).

The severe disorder of the nervous system development such as autism spectrum is a disorder in the children's that impairs with their to interact with each other and communicate. The children with such neurodegenerative disorders like ASD could affected regularly with GI tract problems and may have dysbiosis in microbiota of gut (Yang et al., 2018). A bacteria B. fragilis could improve the behavior of ASD related disorder (Hsiao et al., 2013). In the stress conditions that may cause by certain factors of physical and physiological might directly related with imbalance of microbiota of brain gut (Messaoudi et al., 2011). The consumption of B. longumR0175 and L. Helveticus R0052 may reduce the depression in humans (de la Fuente-Nunez et al., 2017).

In a recent study of changes in the structures of brain were found to be diet dependent in 
the microbiota of the gut by using a machine, the learning classifer that can assess the strength of microbiota associated with brain region. Generally, the mechanisms involving the effect of microbiota of the intestine on the CNS are multifactorial (immunologic, neural and endocrine). These effects are known to be occur via the metabolite's generation by bacterial community (Ong et al., 2018). The SCFAs may alter the nervous system excitability and the microbiota of the gut synthesize a wide range of neurotransmitters, such as acetylcholine, dopamine, $\gamma$-aminobutyric acid, tryptophan and histamine, these are the precursor compounds of serotonin biosynthesis.

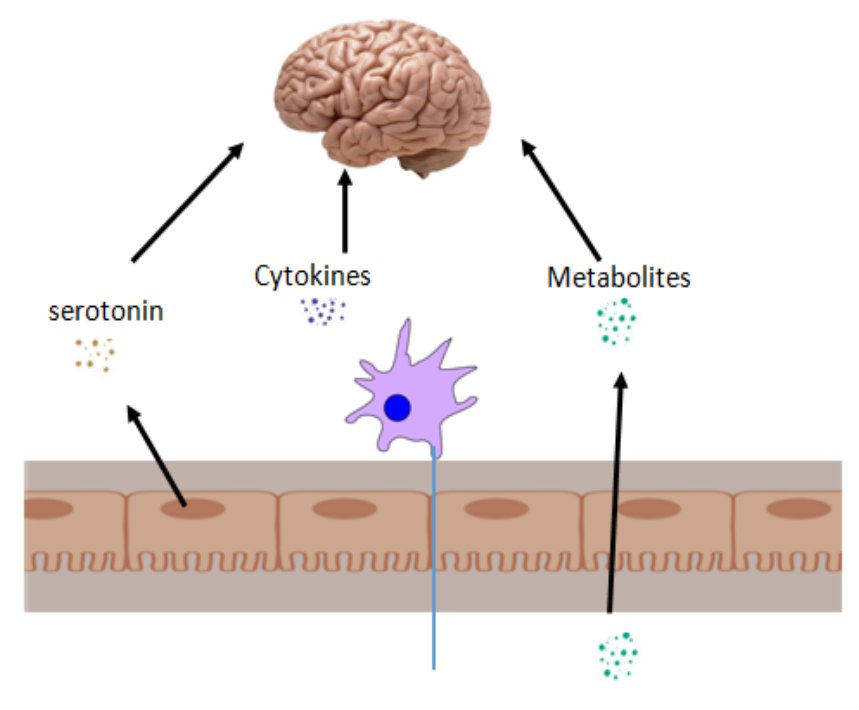

Figure 5. Interaction with Brain Gut Axis

Therapeutic Effects of Probiotics; All of the probiotic microorganisms are not a part of the human gut, therefore the effects of one beneficial species could not relate to other types of species. Besides the beneficial effects of the species their mechanism is not fully known but there are many other modes of action that are known. The basic mechanism of action is the oral ingestion and then they do towards the stomach and pass on to the mucosal membrane and show protection against pathogens in the epithelial membrane. Some probiotics Lactobacillus and Bifidobacterium are known to produce different acids like propionic acid, acetic and lactic acid. These acids play role in lowering the $\mathrm{pH}$ and also prevention from pathogenes growth (Chaucheyras and Durand, 2010). The other type of mechanism is the immune modulation suggested for probiotics modes of action. Recently, in a study from Maryland university school of medicine observe the ingestion of L.rhamnosus GG may contribute in the gut ecosystem via modification of other bacterial activities (Vibhute et al., 2011).

Antibiotic-Associated Diarrhea; It is a clinical condition of diarrhea that is associated with use antibiotics during other diseases. These antibiotics causes the excessive growth of a pathogenic bacteria Clostridium diffcile. Due to this excessive growth the internal 
metabolism of microbial balance may disturb, and this imbalance results in diarrhea (de Vrese and Marteau, 2007). The antibiotics directly affect the intestinal microbiota and terminate the resistance of pathogens thereby facilitating C. diffcileand also growth of other pathogens.

In the treatment of AAD by using probiotics is frequently a tool to assist the probiotics effectiveness and to check the validity of scientific claims on health (Watson and Preedy, 2015). In a meta-analysis it is demonstrated that by using probiotics the diarrhea can be reduced significantly in a randomized trial of 25 episodes. In another study the probiotics drink containing different species such as L.casei, S. thermophiles and L.bulgaricus show a significant reduction of $21.6 \%$ in the AAD (Hickson, 2011).

Irritable Bowel Syndrome (IBS); Irritable bowel syndrome is a functional disease of the gastroenterological system generally characterized as changes in the bowel movement and abdominal pain (Lovell et al., 2010). In the therapeutic treatment option, there are many drugs for IBS such as antibiotics, antispasmodic and anti-depressants, but these drugs may cause certain health problems. However, the new treatment option for this disease is the probiotics. There are many clinical studies that prove the effectiveness of probiotics on this disease, a meta-analysis evaluates the low doses probiotic in a short time period is the most effective treatment (Zhang et al., 2016).

In a recent clinical study the double coated multi species of probiotics containing 5 billion of bacteria per capsule (S. thermophiles,L. plantarum, L. acidophilus, L. plantarum, B. lactis, B. breve, B. longum) the patients show efficacy in IBS and other types of diarrhea (Han et al., 2017). In the meta-analysis of another recent study, using multi-species probiotics with different strains of Bifidobacterium infantis show significant reduction in bloating and abdominal pain. Hence, the treatment by using only single probiotic strain did not show efficacy in IBS (Yuan et al., 2017).

Lactose intolerance; Lactose intolerance is syndrome characterized by the deficiency of lactase enzyme in duodenum cell lining. The other terms such as lactase non-persistence and lactose malabsorption are the conditions in which impairment of the lactase production occur. Alactasia is a condition of complete absence of $\beta$-galactosidase (lactase). This condition is present in people who are unable to digest any product of milk and cannot drink even small amount of the lactose containing product. Mostly this intolerance is found in individuals of European descent. On the other hand, more than 90 $\%$ adult population in Asia suffer from lacrosse intolerance (Vuorisalo et al., 2012).

The use of milk and their products are one of the major calcium sources and also other nutrients found in these products essential for balanced diet. In most of lactose intolerance cases people do not have to completely eliminate dairy products (Suchy et al., 2010).

Scientists demonstrated that one cup milk with their food consumption is necessary in eliminating lactose intolerance. A study demonstrates the Lactobacillus acidophilus effect on individuals influenced with lactose intolerance. The treatment of Lactobacillus acidophilus species DD-1 for almost 4 weeks showed that the symptoms of intolerance such as diarrhea, pain in abdomen and vomiting recorded to be zero, and without 
imposing no side effect (De Vrese 2010). The probiotics may reduce lactose intolerance by increasing lactose hydrolysis in dairy products (Vonk et al., 2012).

Hypercholesterolemia and Coronary Heart Diseases

At present different drugs are used to control the level of serum cholesterol, but if the consumption of these antibioticsretain for long time they may cause undesireable side effects. So, the use of probiotics and dietry fibres increases for lowering the serum cholesterol (Ahmad et al., 2012). The most important mechanism is the binding of bile salts with the walls of intestine through the enzyme bile salt hydrolase. The hydrolase enzyme breaks the de-conjugated bile salts via the probiotics into cholic acid, amino acids and free taurine. These molecules can then be reabsorbed within the intestine and liver and may excrete out from our body (Anandharaj et al., 2014).

Diabetes; It is a multi-factorial disease that is caused by genetic factors and certain environmental factors, the affected population rate is $10 \%-30 \%$ worldwide. The scientific research on diabetes suggested the cause for diabetes development is the insulin resistance due to inflammatory stress and the interaction between intestinal microbes and genetic and environmental factors, that results in diabetes. However, through the new trend in treatment of using probiotics the intestinal microbes are improved to function properly that can help in the maintenance of diabetes. Probiotics help in the maintenance of intestinal microbes and provide an effective treatment option in the insulin resistant related therapies (Ejtahed et al., 2011).

In a meta-analysis of diabetic patients, the effect of probiotic on the blood glucose level and glycemic index of patients was evaluated. In the results it was shown that, both treatments the placebo and with probiotics significantly differ from each other, as there was a reduction in HbAIc, insulin and glucose levels in the patients. It was suggested that using probiotics in dietary supplements the level of blood sugar and other diseases of glucose metabolism can be reduce (Sun and Buys, 2016). Another study on probiotics shown that probiotics have efficacy in type 1 and type 2 diabetic conditions, and it was determine that probiotics proved to be effective in both types of types by modulating the microbes in intestine (de Oliveira et al., 2014).

Cancer (colon tumors); L. acidophilus induction and consumption of fermented colostrum's with L. acidophilus and feeding milk demonstrated the reduction in colon cancer and also results in $41 \%$ decrease of tumor proliferation (Andrews \& Tan 2012). Other types of probiotics such as Bulgaricus also known to have anti-tumor activity in Ehrlich ascites carcinoma and sarcoma-180 (Lee et al., 2012). The mechanism of action of probiotics to induce their activity against tumor proliferation is through 1) the modulation of immune system associated with immune functions 2) Enzymatic activity, to produce that types of enzymes that suppress the activity of pathogens (E. coli, C. difficile) producing enzymes such as urease, azedoreductase, glucuronidase, nitroreductase and hydrolase. These enzymes convert the inactivated carcinogen into their proximate carcinogen form. P. freudenreichii have been shown to cause the cell death in gastric cancer by secreting short chain fatty acids in culture media of human colon cells (Lee et al., 2012). 
Lipid metabolism and cardiovascular diseases; The potential effects by probiotics on lipid metabolism were first suggested by the Mann and Spoerry. They have reported the serum cholesterol reduction in the Northen area peoples of Massai by consuming the fermented milk products (Watson \& Preedy, 2010). Some of the probiotic strains such a L. reuteri, B. coagulans, L. bulgaricus reported to lower the cholesterol level. In human studies the L. acidophilus demonstrate to reduce the serum cholesterol level significantly. The low-fat yogurt consumption containing B. longum in patients with hypercholsterolemia represent significant decline of LDL cholesterol and triglycerides. It was also shown to have $14.5 \%$ increase the level of HDL (Homayouni et al., 2012).

HIV and probiotics; The HIV infection totally alter the microbial colonization and composition of microbiota in oral cavity. HIV decrease the CD 4 cells, a type of T cells that are associated with our oral lesions (Hamza et al., 2006). The progression in HIV infection causes the deregulation in the intestinal microbiota that can also persist in antiretroviral therapy that is highly active. It also affects the gut microbiota dysbiosis associated with the progression of disease (Nowak et al., 2015). The healthy gut microbiota is associated with the overall body health and the alteration in the micro flora of gut responsible for several diseases of humans like metabolic diseases, neurodegenerative diseases and bowel diseases (Baumler \& Sperandio, 2016). The induction of probiotics may reduce the intestinal diseases by increasing the production of mucus, IgA production, anti-microbial peptide, increasing the competitive adhesion of probiotcs on intestinal surface and promoting barrier functions on epithelial cells (Bron et al., 2017). The lactobacilli known to adhere the intestinal mucosal surface by inhibiting pathogenic bacteria adhesion and increasing the production of mucin.

The major site for the proliferation of HIV is gastrointesinal tract and the disorders of intestine are most commonly seen among the HIV patients. The HIV patients are susceptible under the hypoacidity of gastric, that can impose a greater risk for the opportunistic infection. The infection of HIV is causative agent to have adverse side effects on the immune system and its interaction with our commensal microbiota, that can result in the progressive decline in immune system functioning and inefficiency of repair the epithelial layer and increasing the permeability for gastrointestinal disorders (Tincati et al., 2016). The people with AIDS shown o have impaired walls of the intestine, enlargement of the intestinal glands and microvillus atrophy decreases the surface area. The possible reasons for these types of modification are discomfort in digestive system, decreased intake of nutrients and mal absorption. Candida albicans, Pseudomonas aeruginosa, reduce level of Bifidobacteria and Lactobacillus are related with the loss of barrier functions in mucosal membrane and damage the immune system (Perez-Santiago et al., 2013).

When the HIV initial stage infection is in progress, immune system becomes unprepared for viral attack, therefore, HIV infection spread in the whole body. There is disruption of gut microbiota in case of HIV and depletion of CD 4 cells in the thin layer of areolar connective tissue, beneath the epithelium in the acute phase of HIV infection and these cells are shown to more susceptible for HIV. This massive depletion in CD 4 cells is due to high activation level and expression of receptors chemokine (CCR5) in CD 4 cells that are known to produce the interleukin- 17 and IL-22. The depletion of IL-17 and IL-22 
leads to the apoptosis via pyroptosis and directly killing the infected cells as well as increases the natural killer cells by bystander cells and cytotoxic T-cells (Steele et al., 2014). These mechanisms involve the loss of T cells and CD 4 cells, high level of TNF, the receptors of TNFs both 1 and 2, interferons and interleukin (IL-16) are observed (Lindemans et al., 2015).

Administration of probiotics; The probiotics can protect our gut surface and play an important role in the prevention of HIV and AIDS infection progress. The probiotics are an efficient way to potentially control the morbidity as well as mortality in HIV infection and also an inexpensive way of treating the disease (Hummelen et al., 2010). Some of these microbes are associated with our healthy intestinal microflora. The probiotics produce organic acids such as acetic acid and lactic acid as end products in their metabolism. These organic acids shown to have tendency for lowering the intestinal $\mathrm{pH}$ and creating an environment for reducing growth of harmful bacteria. The probiotics secrete anti-microbial peptides to kill pathogens in our gut. They also help to strengthen the barrier functions in gut and intestinal epithelium, and to lower the bacteria in intestine to pass on to the blood stream, this will also decrease the immune infections and other unfavorable reactions of immune system. Thus, probiotics support our immune system to perform healthy functions. As the probiotics knowledge is increasing, the protection of this intestinal microflora becomes necessary. The source of probiotic is from fermented foods, quality supplements (Forseberg et al., 2016). This quality supplements of our diet improves the antioxidant level and help in the reconstruction of our immune system.

Probiotics induce the epithelial healing via altering the micro-flora of intestine, and also prevent the CD 4 cells decline. This may lower the virus transmission risk and reduce co-infection hospitalization. The patients of HIV who are on anti-retroviral therapy fail to process an immunological response such as $C D<200$. They have low lactobacilli level, increased CD 14 and LPS level, and inflammatory level elevation. It results in gut microbiota improvement, and reduction of CD $4+$ cell activation (CD 25) and CD 14. The combination bacteria of probiotic causes the uptake of T regulatory cells and suppresses the pro-inflammatory cytokines production. In this way is provides basis for the probiotic use in HIV treatment. Additionally, the probiotic ability for barrier function improvement and maintenance of homeostasis in intestine also addresses the probiotic strains function to revert the Th-2 polarization induced in HIV infection (Iwabuchi et al., 2009). The HIV infected patients of anti-retroviral therapy when supplemented with probiotics shown to have significant reduction of microbial markers and inflammation (d'Ettorre et al., 2015).

In patients of HIV, the quality supplementation of diet with L. casei for 4 weeks demonstrate the immunological, virological and bacteriological beneficial effects that increases the CD 56+ cells. Thus, decreases the inflammatory response of immune system and significantly enhances the IL-23 serum production. Moreover, the probiotics could be potentially useful for reducing risk factors of heart diseases, hypercholesterolemia. The pobiotic supplementation also useful for quality life improvement by nutritional status improvement, stimulate the functions of immune system and improving the gastrointestinal manifestations (Hummelen et al., 2010). The overgrowth of atypical bacteria in the vagina may increase the transmission and risk of 
HIV aquistion, thus increasing the pro-inflammatory response by disrupting the barrier functions of intestinal mucosa (Staab et al., 2009), and the administration of probiotics may be preventive for attack of bacteria on the vagina (Ryder et al., 2012). Therefore, in the infected patients of HIV, probiotics proved to be inexpensive and more accessible approach for HIV and other perdontal diseases treatment that confer potential effects on the host for improving the life quality (Noguera-Julian et al., 2017).

Kefir probiotic improve cardiac function; The increased risk of cardiovascular diseases and its morbidity or mortality associated with the hypertension (Mills et al., 2016). The persistence of hypertension for long time may leads to the hypertrophy in left ventricle, as a consequence leads to heart failure (Messerli et al., 2017). The cardiac failure is caused, when the neuro humoral pathways becomes hyperactive. Specifically, it increases the activity of sympathetic nervous system, which is compensatory mechanism for initial cardiac system functioning and contractile movement stimulation (De Lucia et al., 2018). The probiotics have the potential for chronic diseases improvement, including hypertension (Pimenta et al., 2018). The mechanisms by which probiotics produce their potential effects by dietry supplements and contribute to promoting the health are very complesx and not completely understood. Recently, the most ideal dairy probiotic kefir shown to have substantial effects on cardiovascular diseases such as they prevent atherosclerosis in mice with hypercholesteremia, also reduces the blood pressure (Santanna et al., 2017).

The mechanisms that involved potential benefits of kefir to reduce hypertension involve the endothelial dysfunction improvement as well as increase the sensitivity of baroreflex and control the autonomic heart rate (Klippel et al., 2016).

Treatment with kefir; In an experiment of three animal groups, control group (WKY) treated with whole milk, SHR (spontaneously hypersensitive rats) group also treated with whole milk (vehicle) and third group SHR-kefir treated with fermented milk by grins of kefir. For 9 weeks animals were daily given the oral administration dose of $0.3 \mathrm{ml} / 100 \mathrm{~g}$ body weight (Friques et al., 2015). With the long term treatment of kefir the blood pressure decreased and mean arterial pressure also reduced $(\mathrm{P}<.01)$ in kefir treated group. The treatment of kefir also reduces hypertrophy of cardiac $(\mathrm{P}<.05)$. The kefir treated group have improve cardiac functions and presented the low level of systolic pressure in left ventricle. The proteins of calcium handling show normalized effect with kefir treatment in hypersensitive animals (Silva-Cutini et al., 2019).

Safety and side effects of Probiotics; The use of probiotics in dairy products as food supplements have been started for more than hundred years ago. These probiotics were used very safely. In recent trend these probiotics are known to have potential to mitigate, treat and for the prevention of some specific diseases. These probiotics are increasingly used in many clinical trials for investigating efficiency of probiotics in a multitude disorders ranging from newborn necrotizing enterocolitis to hypertension and cardiovascular disease in adults (Bernardo et al., 2013). The harmful probiotics effect and their influence of several extraction sources on adverse effects were thoroughly investigated. In accordance with the described results, the subjects suffering from cancer, impaired immune system patients and seriously ill infants are specifically at risk. 


\section{Frontiers in Chemical Sciences (FCS)}

Theoretically, the probiotics account for several types of side effects. According to WHO there should be an array of clinical tests for analyzing, production of toxic substances, resistance to antibiotics, metabolic activities and potential to hemolytic anemia for safety consideration. Meanwhile, it is emphasized on the supervisor of post market of consumers to observe the infectivity of probiotics and also study the applications of probiotics in impaired immune system of animals to investigate their efficacy and side effects (FAO/WHO working group, 2002). The following figure 6 depicted the summary of some potential harmful effects regarding probiotics use.

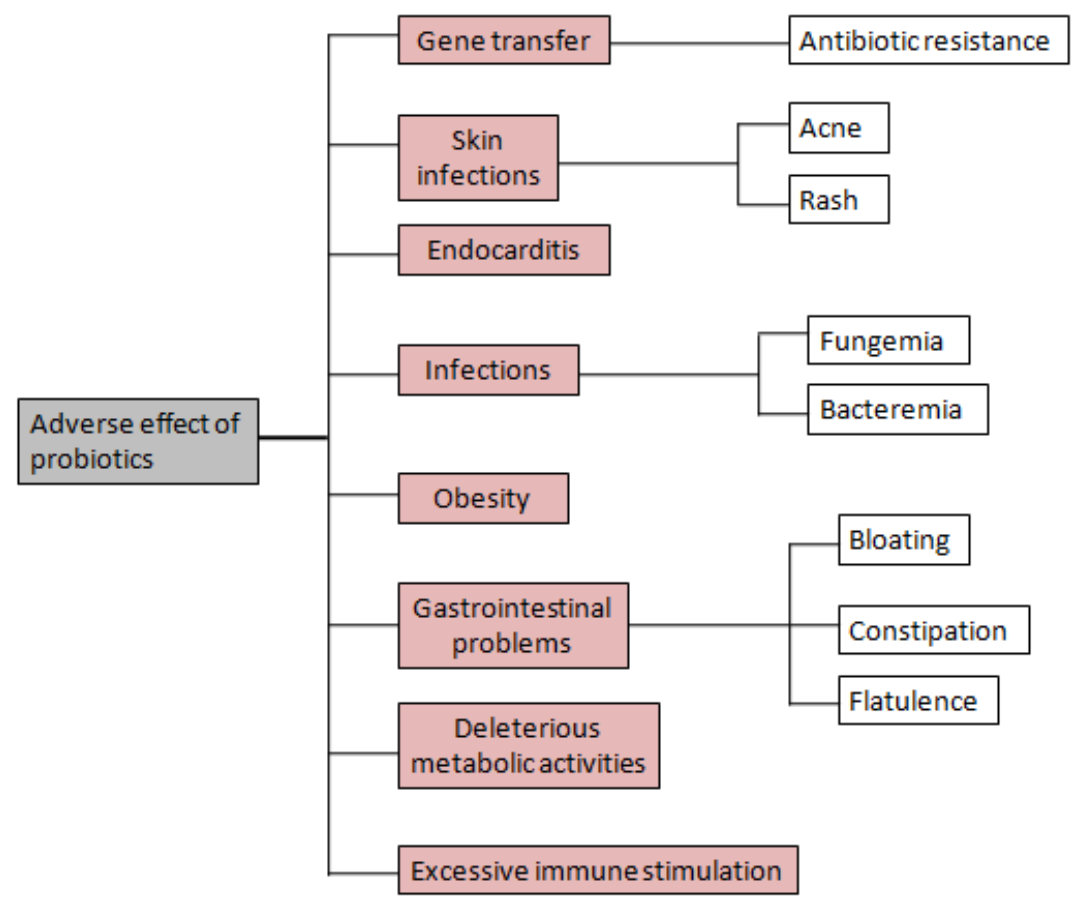

Figure 6. Adverse Effects of Probiotics

(Kara et al., 2018).

Bacteremia; There are also some cases that reports the presence of bacteremia as a result of three different strains of probiotic Lactobacillus casei, Lactobacillus GG and Lactobacillus acidophilus (Splichalova et al., 2019). In the meanwhile, there are many cases have been reported for overt sepsis (Watson \& preedy, 2015). The analysis of predisposing factors outcome regarding Lactobacillus bacteremia were conduted in a trial in years 1990-2000. In all these conducted trials the Lactobacillus strain L. rhamnosus has been significantly observed to produce bacteremia. Moreover, the effect of bacteremia demonstrate two types of mechanisms, the first type is the antagonistic nature regarding use of probiotics to decrease the invasion of pathogens. This effect can be 
resolve through the short chain fatty acids production, in low $\mathrm{pH}$, increasing antioxidant activity and producing anti-microbial peptides. The second one illustrate that, probiotics completely occupy the niches but in case, if some niches remain empty the pathogens may avail this empty place, invade and may cause any infection (Vandenplas et al., 2015).

Gastrointestinal side effects; Some GI infections have also reported such as spasm, taste disturbance, different kinds of diarrhea, nausea, thirst and constipation. These are happen in administration of probiotics (Golgenberg et al., 2017).

Constipation or Diarrhea; The current research illustrates the probiotic efficacy in the treatment of diarrhea. It is shown that, the consumption of newly developed probiotic supplements during the first 3 days, the GI stimulated and may become more susceptible for mild type of diarrhea. In study, the S. boulardi was found to cause constipation (Johnston et al., 2012).

Gastrointestinal ischemia; In one study, the probiotic effects were evaluated with certain inflammation in pancreas showing complications in patients. The gastric ischemia related mortality and morbidity was observed in the patients who was subjected to probiotic treatment with the aim of effective results. It was hypothesized that the patients with gastric ischemia, who were administered probiotics suggested that there may be demand of oxygen in the mucosa of intestine that was may be due to reduced flow of blood in probiotic administration. Regarding the use of probiotics, the impact on pancreas inflammation was observed by giving the patients a multi-strain dose of probiotics composed of four strains from Lactobacilli and two from Bifidobacterium. The 291 patients with pancreatitis were administered this dose for 28 days and they were observed for 90 days. Unexpectedly, the 8 patients out of 9 were died with bowel ischemia during therapy (Besselink et al., 2008).

Excessive immune stimulation; The innate and adaptive immune system, both have been known to influence largely by the probiotics. These mechanisms involve the activity of dendritic cells, production of anti-inflammatory cytokines. A concern is present about the use of probiotics to produce an inflammatory response and developing autoimmune disorders in subjects that are treated to show potential effects of probiotics. Some of the study on animals, the immune system was affected showing certain effects such as non alcoholic fatty liver disease, NF-kB and c-JNK signalling. However, in case of humans no report was shown regarding these effects about this concern (Wai-Sun Wong et al., 2015).

Transfer of genes in pathogens from probiotics; Another concern regarding the safety of probiotics use results from the transfer of gene having antibiotic resistance from probiotics Bifidobacterium and Lactobacilli species into pathogenic bacteria present in our intestinal microflora (Margo et al., 2014). The attempts were made on the transfer of genes from Enterococci to Lactobacilli and Lactococci in animals intestine, but there was no such successful attempt was seen to transfer genes into Lactobacilli. In a general rule, the probiotics should be checked before the use in human or animal case, they must be free of any kind of transferable genes of antibacterial resistant. 
Endocarditis; There are many reports that address the infection of endocardium, which could be due to probiotic strain Lactobacillus and Streptococcus. The Endocarditis progress in using Lactobacillus rhamnosus was reported in the documents (Boumis et al., 2018).

Skin side effects; In the use of probiotics to patients, the skin problems may occur such as acne and rashes are mostly detected. However, the rashes on skin might be result from the body's mechanism to remove toxins and reduce the infection but on the other hand, some probiotics not only induce the mild acne and rashes on skin but at the same time they change the normal microfloa of our skin that results in the complications (Salminen et al., 2004).

Harmful metabolic effects; There may be some metabolic infectivity in case of using probiotics such as producing metabolites of D-lactate by some probiotic strains. The production of D-lactate is an indication of D-lactitc acidosis in patients receiving probiotics who are suffering from bile acid malabsorption (Ng et al., 2017).

\section{Conclusions}

Probiotics are good bacteria that are safe when we administered in adequate amount and in proper time periods. These bacteria confer positive effect on the host metabolism. They have different modes of action by which they confer their activity such as the perturbed microbes normalization in the intestine, modulation of enzymatic activities, immune mechanisms modulation by producing anti-inflammatory response, cell adhesion, bacteriocin production, maintenance of homeostasis and enhancing the activity of lymphoid tissues around the gut. Probiotics also have ability to interact with brain gut axis and improve behavioral problems. Hence, due to these modes of action probiotics are used in many clinical conditions for the treatment of digestive system diseases such as different types of diarrhea and other chronic syndromes involving HIV that may leads to AIDS if remain untreated. All these methods of probiotic action should give confidence to the researchers for further investigation of different strains of bacteria that show beneficial and promising outcomes.

\section{References}

Aagaard, K., Ma, J., Antony, K. M., Ganu, R., Petrosino, J., \& Versalovic, J. (2014). The placenta harbors a unique microbiome. Science translational medicine, 6(237), 237ra65-237ra65.

Ahmad, A., Munir, B., Abrar, M., Bashir, S., Adnan, M., \& Tabassum, T. (2012). Perspective of $\beta$-glucan as functional ingredient for food industry. J Nutr Food Sci, 2(2).

Aktas, B., De Wolfe, T. J., Safdar, N., Darien, B. J., \& Steele, J. L. (2016). The impact of Lactobacillus casei on the composition of the cecal microbiota and innate immune system is strain specific. PloS one, 11(5), e0156374.

Anandharaj, M., Sivasankari, B., \& Parveen Rani, R. (2014). Effects of probiotics, prebiotics, and synbiotics on hypercholesterolemia: a review. Chinese Journal of Biology, 2014.

Bäumler, A. J., \& Sperandio, V. (2016). Interactions between the microbiota and pathogenic bacteria in the gut. Nature, 535(7610), 85-93.

Bermudez-Brito, M., Plaza-Díaz, J., Muñoz-Quezada, S., Gómez-Llorente, C., \& Gil, A. 
(2012). Probiotic mechanisms of action. Annals of Nutrition and Metabolism, 61(2), 160-174.

Bermudez-Brito, M., Plaza-Díaz, J., Muñoz-Quezada, S., Gómez-Llorente, C., \& Gil, A. (2012). Probiotic mechanisms of action. Annals of Nutrition and Metabolism, 61(2), 160-174.

Bernardo, W. M., Aires, F. T., Carneiro, R. M., de Sá, F. P., Rullo, V. E. V., \& Burns, D. A. (2013). Effectiveness of probiotics in the prophylaxis of necrotizing enterocolitis in preterm neonates: a systematic review and meta-analysis. Jornal de Pediatria (Versão em Português), 89(1), 18-24.

Boumis, E., Capone, A., Galati, V., Venditti, C., \& Petrosillo, N. (2018). Probiotics and infective endocarditis in patients with hereditary hemorrhagic telangiectasia: a clinical case and a review of the literature. BMC infectious diseases, 18(1), 65.

Bron, P. A., Kleerebezem, M., Brummer, R. J., Cani, P. D., Mercenier, A., MacDonald, T. T., ... \& Wells, J. M. (2017). Can probiotics modulate human disease by impacting intestinal barrier function?. British Journal of Nutrition, 117(1), 93107.

Buss, C., Valle-Tovo, C., Miozzo, S., \& Alves de Mattos, A. (2015). Probiotics and synbiotics may improve liver aminotransferases levels in non-alcoholic fatty liver disease patients. Annals of hepatology, 13(5), 482-488.

Canfora, E. E., Jocken, J. W., \& Blaak, E. E. (2015). Short-chain fatty acids in control of body weight and insulin sensitivity. Nature Reviews Endocrinology, 11(10), 577.

Cecic, A., \& Chingwaru, W. (2010). The Role of Functional Foods. Nutraceuticals, and Food Supplements in Intestinal Health. Nutrients, 2, 611-625.

Chaucheyras-Durand, F., \& Durand, H. (2009). Probiotics in animal nutrition and health. Beneficial microbes, 1(1), 3-9.

Claes, A. K., Zhou, J. Y., \& Philpott, D. J. (2015). NOD-like receptors: guardians of intestinal mucosal barriers. Physiology, 30(3), 241-250.

Collado, M. C., Gueimonde, M., \& Salminen, S. (2010). Probiotics in adhesion of pathogens: mechanisms of action. In Bioactive Foods in Promoting Health (pp. 353-370). Academic Press.

Collado, M. C., Gueimonde, M., \& Salminen, S. (2010). Probiotics in adhesion of pathogens: mechanisms of action. In Bioactive Foods in Promoting Health (pp. 353-370). Academic Press.

D’Amelio, P., \& Sassi, F. (2018). Gut microbiota, immune system, and bone. Calcified tissue international, 102(4), 415-425.

d'Ettorre, G., Ceccarelli, G., Giustini, N., Serafino, S., Calantone, N., De Girolamo, G., ... \& Turriziani, O. (2015). Probiotics reduce inflammation in antiretroviral treated, HIV-infected individuals: results of the "Probio-HIV" clinical trial. PLoS One, 10(9), e0137200.

de la Fuente-Nunez, C., Meneguetti, B. T., Franco, O. L., \& Lu, T. K. (2017). Neuromicrobiology: how microbes influence the brain. ACS chemical neuroscience, 9(2), 141-150.

De Lucia, C., Eguchi, A., \& Koch, W. J. (2018). New insights in cardiac $\beta$-adrenergic signaling during heart failure and aging. Frontiers in pharmacology, 9, 904.

de Oliveira, M. E. G., Garcia, E. F., de Oliveira, C. E. V., Gomes, A. M. P., Pintado, M. M. E., Madureira, A. R. M. F., ... \& de Souza, E. L. (2014). Addition of 
probiotic bacteria in a semi-hard goat cheese (coalho): Survival to simulated gastrointestinal conditions and inhibitory effect against pathogenic bacteria. Food Research International, 64, 241-247

De Vrese, M., \& Offick, B. (2010). Probiotics and prebiotics: effects on diarrhea. In Bioactive Foods in Promoting Health (pp. 205-227). Academic Press.

De Vrese, M., \& Offick, B. (2010). Probiotics and prebiotics: effects on diarrhea. In Bioactive Foods in Promoting Health (pp. 205-227). Academic Press.

Dogi, C., García, G., De Moreno de LeBlanc, A., Greco, C., \& Cavaglieri, L. (2016). Lactobacillus rhamnosus RC007 intended for feed additive: immune-stimulatory properties and ameliorating effects on TNBS-induced colitis. Beneficial microbes, 7(4), 539-547.

Ejtahed, H. S., Mohtadi Nia, J., Homayouni Rad, A., Niafar, M., Asghari Jafarabadi, M., \& Mofid, V. (2011). The effects of probiotic and conventional yoghurt on diabetes markers and insulin resistance in type 2 diabetic patients: a randomized controlled clinical trial. Iranian journal of endocrinology and metabolism, 13(1), 112.

Forsberg, A., West, C. E., Prescott, S. L., \& Jenmalm, M. C. (2016). Pre-and probiotics for allergy prevention: time to revisit recommendations?. Clinical \& Experimental Allergy, 46(12), 1506-1521.

Friques, A. G., Arpini, C. M., Kalil, I. C., Gava, A. L., Leal, M. A., Porto, M. L., ... \& Meyrelles, S. S. (2015). Chronic administration of the probiotic kefir improves the endothelial function in spontaneously hypertensive rats. Journal of translational medicine, 13(1), 390.

Fujiya, M., Ueno, N., \& Kohgo, Y. (2014). Probiotic treatments for induction and maintenance of remission in inflammatory bowel diseases: a meta-analysis of randomized controlled trials. Clinical journal of gastroenterology, 7(1), 1-13.

Ganji-Arjenaki, M., \& Rafieian-Kopaei, M. (2018). Probiotics are a good choice in remission of inflammatory bowel diseases: A meta analysis and systematic review. Journal of cellular physiology, 233(3), 2091-2103.

Geirnaert, A., Calatayud, M., Grootaert, C., Laukens, D., Devriese, S., Smagghe, G., ... \& Van de Wiele, T. (2017). Butyrate-producing bacteria supplemented in vitro to Crohn's disease patient microbiota increased butyrate production and enhanced intestinal epithelial barrier integrity. Scientific reports, 7(1), 11450.

Giorgetti, G., Brandimarte, G., Fabiocchi, F., Ricci, S., Flamini, P., Sandri, G., ... \& Picchio, M. (2015). Interactions between innate immunity, microbiota, and probiotics. Journal of immunology research, 2015.

Gómez-Llorente, C., Munoz, S., \& Gil, A. (2010). Role of Toll-like receptors in the development of immunotolerance mediated by probiotics. Proceedings of the Nutrition Society, 69(3), 381-389.

Gómez-Llorente, C., Munoz, S., \& Gil, A. (2010). Role of Toll-like receptors in the development of immunotolerance mediated by probiotics. Proceedings of the Nutrition Society, 69(3), 381-389.

Hamza, O. J., Matee, M. I., Simon, E. N., Kikwilu, E., Moshi, M. J., Mugusi, F., ... \& van der Ven, A. J. (2006). Oral manifestations of HIV infection in children and adults receiving highly active anti-retroviral therapy [HAART] in Dar es Salaam, Tanzania. BMC oral health, 6(1), 12.

Han, K., Wang, J., Seo, J. G., \& Kim, H. (2017). Efficacy of double-coated probiotics for 
irritable bowel syndrome: a randomized double-blind controlled trial. Journal of gastroenterology, 52(4), 432-443.

Harbige, L. S., Pinto, E., Allgrove, J., \& Thomas, L. V. (2016). Immune response of healthy adults to the ingested probiotic Lactobacillus casei Shirota. Scandinavian journal of immunology, 84(6), 353-364.

Hempel, S., Newberry, S. J., Maher, A. R., Wang, Z., Miles, J. N., Shanman, R., ... \& Shekelle, P. G. (2012). Probiotics for the prevention and treatment of antibioticassociated diarrhea: a systematic review and meta-analysis. Jama, 307(18), 1959-1969.

Hesla, H. M., Stenius, F., Jäderlund, L., Nelson, R., Engstrand, L., Alm, J., \& Dicksved, J. (2014). Impact of lifestyle on the gut microbiota of healthy infants and their mothers-the ALADDIN birth cohort. FEMS microbiology ecology, 90(3), 791801.

Hevia, A., Delgado, S., Sánchez, B., \& Margolles, A. (2015). Molecular players involved in the interaction between beneficial bacteria and the immune system. Frontiers in microbiology, 6, 1285.

Hickson, M. (2011). Probiotics in the prevention of antibiotic-associated diarrhoea and Clostridium difficile infection. Therapeutic advances in gastroenterology, 4(3), 185-197.

Hojsak, I., Szajewska, H., Canani, R. B., Guarino, A., Indrio, F., Kolacek, S., ... \& Weizman, Z. (2018). Probiotics for the prevention of nosocomial diarrhea in children. Journal of pediatric gastroenterology and nutrition, 66(1), 3-9.

Homayouni, A., Payahoo, L., \& Azizi, A. (2012). Effects of probiotics on lipid profile: A review. American Journal of Food Technology, 7(5), 251-265.

Hsiao, E. Y., McBride, S. W., Hsien, S., Sharon, G., Hyde, E. R., McCue, T., ... \& Patterson, P. H. (2013). Microbiota modulate behavioral and physiological abnormalities associated with neurodevelopmental disorders. Cell, 155(7), 14511463.

Hummelen, R., Vos, A. P., Land, B. V. T., Norren, K. V., \& Reid, G. (2010). Altered host-microbe interaction in HIV: a target for intervention with pro-and prebiotics. International reviews of immunology, 29(5), 485-513.

Hur, K. Y., \& Lee, M. S. (2015). Gut microbiota and metabolic disorders. Diabetes \& metabolism journal, 39(3), 198-203.

Iwabuchi, N., Takahashi, N., Xiao, J. Z., Yonezawa, S., Yaeshima, T., Iwatsuki, K., \& Hachimura, S. (2009). Suppressive effects of Bifidobacterium longum on the production of Th2-attracting chemokines induced with T cell-antigen-presenting cell interactions. FEMS Immunology \& Medical Microbiology, 55(3), 324-334.

Johnston, B. C., Ma, S. S., Goldenberg, J. Z., Thorlund, K., Vandvik, P. O., Loeb, M., \& Guyatt, G. H. (2012). Probiotics for the prevention of Clostridium difficileassociated diarrhea: a systematic review and meta-analysis. Annals of internal medicine, 157(12), 878-888.

Kara, I., Yıldırım, F., Özgen, Ö., Erganiş, S., Aydoğdu, M., Dizbay, M., ... \& Kalkanci, A. (2018). Saccharomyces cerevisiae fungemia after probiotic treatment in an intensive care unit patient. Journal de mycologie medicale, 28(1), 218-221.

Kaufmann, S. H. (2008). Immunology's foundation: the 100-year anniversary of the Nobel Prize to Paul Ehrlich and Elie Metchnikoff. Nature immunology, 9(7), 705 . 
Klippel, B. F., Duemke, L. B., Leal, M. A., Friques, A. G., Dantas, E. M., Dalvi, R. F., ... \& Campagnaro, B. P. (2016). Effects of kefir on the cardiac autonomic tones and baroreflex sensitivity in spontaneously hypertensive rats. Frontiers in physiology, 7, 211.

Kumar, M., Dhaka, P., Vijay, D., Vergis, J., Mohan, V., Kumar, A., ... \& Rawool, D. B. (2016). Antimicrobial effects of Lactobacillus plantarum and Lactobacillus acidophilus against multidrug-resistant enteroaggregative Escherichia coli. International journal of antimicrobial agents, 48(3), 265-270.

Kumar, M., Nagpal, R., Verma, V., Kumar, A., Kaur, N., Hemalatha, R., ... \& Singh, B. (2013). Probiotic metabolites as epigenetic targets in the prevention of colon cancer. Nutrition reviews, 71(1), 23-34.

Kumar, R., Grover, S., \& Batish, V. K. (2011). Hypocholesterolaemic effect of dietary inclusion of two putative probiotic bile salt hydrolase-producing Lactobacillus plantarum strains in Sprague-Dawley rats. British Journal of Nutrition, 105(4), 561-573.

Kwon, H. K., Lee, C. G., So, J. S., Chae, C. S., Hwang, J. S., Sahoo, A., ... \& Im, S. H. (2010). Generation of regulatory dendritic cells and CD4+ Foxp3+ T cells by probiotics administration suppresses immune disorders. Proceedings of the National Academy of Sciences, 107(5), 2159-2164.

Larsen, N., Vogensen, F. K., Gøbel, R. J., Michaelsen, K. F., Forssten, S. D., Lahtinen, S. J., \& Jakobsen, M. (2013). Effect of Lactobacillus salivarius Ls-33 on fecal microbiota in obese adolescents. Clinical nutrition, 32(6), 935-940.

Lee, S. Y., Lee, S. J., Choi, D. S., \& Hur, S. J. (2015). Current topics in active and intelligent food packaging for preservation of fresh foods. Journal of the Science of Food and Agriculture, 95(14), 2799-2810.

Letnická, A., Karaffová, V., Levkut, M., Revajová, V., \& Herich, R. (2017). Influence of oral application of Enterococcus faecium AL41 on TGF- $\beta 4$ and IL-17 expression and immunocompetent cell distribution in chickens challenged with Campylobacter jejuni. Acta Veterinaria Hungarica, 65(3), 317-326.

Lindemans, C. A., Calafiore, M., Mertelsmann, A. M., O’connor, M. H., Dudakov, J. A., Jenq, R. R., ... \& Ivanov, J. A. (2015). Interleukin-22 promotes intestinal-stemcell-mediated epithelial regeneration. Nature, 528(7583), 560.

Lovell, D., Muller, W., Taylor, J., Zwart, A., \& Helliwell, C. (2010). Caution! Compositions!. Report Number: EP10994. CSIRO Mathematical and Information Sciences.

Magro, D. O., de Oliveira, L. M. R., Bernasconi, I., de Souza Ruela, M., Credidio, L., Barcelos, I. K., ... \& Ouwehand, A. C. (2014). Effect of yogurt containing polydextrose, Lactobacillus acidophilus NCFM and Bifidobacterium lactis HN019: a randomized, double-blind, controlled study in chronic constipation. Nutrition journal, 13(1), 75.

McConnell, E. L., Liu, F., \& Basit, A. W. (2009). Colonic treatments and targets: issues and opportunities. Journal of drug targeting, 17(5), 335-363.

Mendes, M. C. S., Paulino, D. S., Brambilla, S. R., Camargo, J. A., Persinoti, G. F., \& Carvalheira, J. B. C. (2018). Microbiota modification by probiotic supplementation reduces colitis associated colon cancer in mice. World journal of gastroenterology, 24(18), 1995.

Messaoudi, M., Lalonde, R., Violle, N., Javelot, H., Desor, D., Nejdi, A., ... \& Cazaubiel, 
J. M. (2011). Assessment of psychotropic-like properties of a probiotic formulation (Lactobacillus helveticus R0052 and Bifidobacterium longum R0175) in rats and human subjects. British Journal of Nutrition, 105(5), 755764.

Messerli, F. H., Rimoldi, S. F., \& Bangalore, S. (2017). The transition from hypertension to heart failure: contemporary update. JACC: Heart Failure, 5(8), 543-551.

Mills, K. T., Bundy, J. D., Kelly, T. N., Reed, J. E., Kearney, P. M., Reynolds, K., ... \& He, J. (2016). Global disparities of hypertension prevalence and control: a systematic analysis of population-based studies from 90 countries. Circulation, 134(6), 441-450.

Mokoena, M. P. (2017). Lactic acid bacteria and their bacteriocins: Classification, biosynthesis and applications against uropathogens: A minireview. Molecules, 22(8), 1255.

Mujagic, Z., De Vos, P., Boekschoten, M. V., Govers, C., Pieters, H. J. H., De Wit, N. J., ... \& Troost, F. J. (2017). The effects of Lactobacillus plantarum on small intestinal barrier function and mucosal gene transcription; a randomized doubleblind placebo controlled trial. Scientific reports, 7, 40128

Munoz-Quezada, S., Bermudez-Brito, M., Chenoll, E., Genovés, S., Gomez-Llorente, C., Plaza-Diaz, J., ... \& Gil, A. (2013). Competitive inhibition of three novel bacteria isolated from faeces of breast milk-fed infants against selected enteropathogens. British Journal of Nutrition, 109(S2), S63-S69.

Murphy, K., Curley, D., O'Callaghan, T. F., O’Shea, C. A., Dempsey, E. M., O’Toole, P. W., ... \& Stanton, C. (2017). The composition of human milk and infant faecal microbiota over the first three months of life: a pilot study. Scientific reports, 7 , 40597.

Ng, Q. X., Soh, A. Y. S., Venkatanarayanan, N., Ho, C. Y. X., Lim, D. Y., \& Yeo, W. S. (2019). A systematic review of the effect of probiotic supplementation on schizophrenia symptoms. Neuropsychobiology, 78(1), 1-6.

Noguera-Julian, M., Guillén, Y., Peterson, J., Reznik, D., Harris, E. V., Joseph, S. J., ... \& Mutembo, S. (2017). Oral microbiome in HIV-associated periodontitis. Medicine, 96(12).

Nowak, P., Troseid, M., Avershina, E., Barqasho, B., Neogi, U., Holm, K., ... \& Rudi, K. (2015). Gut microbiota diversity predicts immune status in HIV-1 infection. Aids, 29(18), 2409-2418.

Nowak, P., Troseid, M., Avershina, E., Barqasho, B., Neogi, U., Holm, K., ... \& Rudi, K. (2015). Gut microbiota diversity predicts immune status in HIV-1 infection. Aids, 29(18), 2409-2418.

Olivares, M., Díaz-Ropero, M. P., Gómez, N., Lara-Villoslada, F., Sierra, S., Maldonado, J. A., ... \& Xaus, J. (2006). Oral administration of two probiotic strains, Lactobacillus gasseri CECT5714 and Lactobacillus coryniformis CECT5711, enhances the intestinal function of healthy adults. International journal of food microbiology, 107(2), 104-111.

Olivares, M., Díaz-Ropero, M. P., Gómez, N., Lara-Villoslada, F., Sierra, S., Maldonado, J. A., ... \& Xaus, J. (2006). Oral administration of two probiotic strains, Lactobacillus gasseri CECT5714 and Lactobacillus coryniformis CECT5711, enhances the intestinal function of healthy adults. International journal of food microbiology, 107(2), 104-111. 
Ong, I. M., Gonzalez, J. G., McIlwain, S. J., Sawin, E. A., Schoen, A. J., Adluru, N., ... \& John-Paul, J. Y. (2018). Gut microbiome populations are associated with structure-specific changes in white matter architecture. Translational psychiatry, 8(1), 6 .

Pärtty, A., Lehtonen, L., Kalliomäki, M., Salminen, S., \& Isolauri, E. (2015). Probiotic Lactobacillus rhamnosus GG therapy and microbiological programming in infantile colic: a randomized, controlled trial. Pediatric research, 78(4), 470.

Pérez-Santiago, J., Gianella, S., Massanella, M., Spina, C. A., Karris, M. Y., Var, S. R., ... \& Richman, D. D. (2013). Gut Lactobacillales are associated with higher CD4 and less microbial translocation during HIV infection. AIDS (London, England), 27(12), 1921.

Pimenta, F. S., Luaces-Regueira, M., Ton, A. M., Campagnaro, B. P., Campos-Toimil, M., Pereira, T. M., \& Vasquez, E. C. (2018). Mechanisms of action of kefir in chronic cardiovascular and metabolic diseases. Cellular Physiology and Biochemistry, 48(5), 1901-1914.

Plaza-Diaz, J., Gomez-Llorente, C., Campaña-Martin, L., Matencio, E., Ortuño, I., Martínez-Silla, R., ... \& Genovés, S. (2013). Safety and immunomodulatory effects of three probiotic strains isolated from the feces of breast-fed infants in healthy adults: SETOPROB study. PLoS One, 8(10), e78111.

Plaza-Diaz, J., Ruiz-Ojeda, F. J., Gil-Campos, M., \& Gil, A. (2019). Mechanisms of action of probiotics. Advances in Nutrition, 10 (suppl_1), S49-S66.

Plaza-Díaz, J., Ruiz-Ojeda, F. J., Gil-Campos, M., \& Gil, A. (2018). Immune-mediated mechanisms of action of probiotics and synbiotics in treating pediatric intestinal diseases. Nutrients, 10(1), 42.

Rajkumar, H., Mahmood, N., Kumar, M., Varikuti, S. R., Challa, H. R., \& Myakala, S. P. (2014). Effect of probiotic (VSL\# 3) and omega-3 on lipid profile, insulin sensitivity, inflammatory markers, and gut colonization in overweight adults: a randomized, controlled trial. Mediators of inflammation, 2014.

Ren, C., Zhang, Q., De Haan, B. J., Zhang, H., Faas, M. M., \& De Vos, P. (2016). Identification of TLR2/TLR6 signalling lactic acid bacteria for supporting immune regulation. Scientific reports, 6, 34561.

Ribet, D., \& Cossart, P. (2015). How bacterial pathogens colonize their hosts and invade deeper tissues. Microbes and infection, 17(3), 173-183.

Ryder, M. I., Nittayananta, W., Coogan, M., Greenspan, D., \& Greenspan, J. S. (2012). Periodontal disease in HIV/AIDS. Periodontology 2000, 60(1), 78-97.

Sa'ad, H., Peppelenbosch, M. P., Roelofsen, H., Vonk, R. J., \& Venema, K. (2010). Biological effects of propionic acid in humans; metabolism, potential applications and underlying mechanisms. Biochimica et Biophysica Acta (BBA)Molecular and Cell Biology of Lipids, 1801(11), 1175-1183.

Saez-Lara, M. J., Gomez-Llorente, C., Plaza-Diaz, J., \& Gil, A. (2015). The role of probiotic lactic acid bacteria and bifidobacteria in the prevention and treatment of inflammatory bowel disease and other related diseases: a systematic review of randomized human clinical trials. BioMed research international, 2015.

Sáez-Lara, M., Robles-Sanchez, C., Ruiz-Ojeda, F., Plaza-Diaz, J., \& Gil, A. (2016). Effects of probiotics and synbiotics on obesity, insulin resistance syndrome, type 2 diabetes and non-alcoholic fatty liver disease: a review of human clinical trials. International journal of molecular sciences, 17(6), 928. 
Salminen, S. (2017). Regulatory Aspects of Human Milk Oligosaccharides. In Intestinal microbiome: functional aspects in health and disease (Vol. 88, pp. 161-170). Karger Publishers.

Salminen, S. (2017). Regulatory Aspects of Human Milk Oligosaccharides. In Intestinal microbiome: functional aspects in health and disease (Vol. 88, pp. 161-170). Karger Publishers.

Santanna, A. F., Filete, P. F., Lima, E. M., Porto, M. L., Meyrelles, S. S., Vasquez, E. C., ... \& Andrade, T. U. (2017). Chronic administration of the soluble, nonbacterial fraction of kefir attenuates lipid deposition in LDLr-/- mice. Nutrition, 35, 100105.

Sharafedtinov, K. K., Plotnikova, O. A., Alexeeva, R. I., Sentsova, T. B., Songisepp, E., Stsepetova, J., ... \& Mikelsaar, M. (2013). Hypocaloric diet supplemented with probiotic cheese improves body mass index and blood pressure indices of obese hypertensive patients-a randomized double-blind placebo-controlled pilot study. Nutrition journal, 12(1), 138.

Sierra, S., Lara-Villoslada, F., Sempere, L., Olivares, M., Boza, J., \& Xaus, J. (2010). Intestinal and immunological effects of daily oral administration of Lactobacillus salivarius CECT5713 to healthy adults. Anaerobe, 16(3), 195-200.

Sierra, S., Lara-Villoslada, F., Sempere, L., Olivares, M., Boza, J., \& Xaus, J. (2010). Intestinal and immunological effects of daily oral administration of Lactobacillus salivarius CECT5713 to healthy adults. Anaerobe, 16(3), 195-200.

Silva-Cutini, M. A., Almeida, S. A., Nascimento, A. M., Abreu, G. R., Bissoli, N. S., Lenz, D., ... \& Andrade, T. U. (2019). Long-term treatment with kefir probiotics ameliorates cardiac function in spontaneously hypertensive rats. The Journal of nutritional biochemistry, 66, 79-85.

Staab, B., Eick, S., Knöfler, G., \& Jentsch, H. (2009). The influence of a probiotic milk drink on the development of gingivitis: a pilot study. Journal of clinical periodontology, 36(10), 850-856.

Steele, A. K., Lee, E. J., Manuzak, J. A., Dillon, S. M., Beckham, J. D., McCarter, M. D., ... \& Wilson, C. C. (2014). Microbial exposure alters HIV-1-induced mucosal CD4+ T cell death pathways Ex vivo. Retrovirology, 11(1), 14.

Suchy, F. J., Brannon, P. M., Carpenter, T. O., Fernandez, J. R., Gilsanz, V., Gould, J. B., ... \& Miller, N. J. (2010). NIH consensus development conference statement: Lactose intolerance and health. NIH consensus and state-of-the-science statements, 27(2), 1-27.

Sun, J., \& Buys, N. J. (2016). Glucose-and glycaemic factor-lowering effects of probiotics on diabetes: a meta-analysis of randomised placebo-controlled trials. British Journal of Nutrition, 115(7), 1167-1177.

Szajewska, H. (2016). What are the indications for using probiotics in children?. Archives of disease in childhood, 101(4), 398-403.

Takeda, S., Kawahara, S., HIDAKA, M., Yoshida, H., Watanabe, W., Takeshita, M., ... \& Kurokawa, M. (2013). Effects of oral administration of probiotics from Mongolian dairy products on the Th1 immune response in mice. Bioscience, biotechnology, and biochemistry, 77(7), 1372-1378.

Tillisch, K., Labus, J., Kilpatrick, L., Jiang, Z., Stains, J., Ebrat, B., ... \& Mayer, E. A. (2013). Consumption of fermented milk product with probiotic modulates brain activity. Gastroenterology, 144(7), 1394-1401. 
Frontiers in Chemical Sciences (FCS)

Tincati, C., Douek, D. C., \& Marchetti, G. (2016). Gut barrier structure, mucosal immunity and intestinal microbiota in the pathogenesis and treatment of HIV infection. AIDS research and therapy, 13(1), 19.

Tsilingiri, K., Barbosa, T., Penna, G., Caprioli, F., Sonzogni, A., Viale, G., \& Rescigno, M. (2012). Probiotic and postbiotic activity in health and disease: comparison on a novel polarised ex-vivo organ culture model. Gut, 61(7), 1007-1015.

Tung, J., Barreiro, L. B., Burns, M. B., Grenier, J. C., Lynch, J., Grieneisen, L. E., ... \& Archie, E. A. (2015). Social networks predict gut microbiome composition in wild baboons. elife, 4 , e05224.

Umu, Ö. C., Rudi, K., \& Diep, D. B. (2017). Modulation of the gut microbiota by prebiotic fibres and bacteriocins. Microbial ecology in health and disease, 28(1), 1348886.

Van Tassell, M. L., \& Miller, M. J. (2011). Lactobacillus adhesion to mucus. Nutrients, 3(5), 613-636.

Vandenplas, Y., Huys, G., \& Daube, G. (2015). Probiotics: an update. Jornal de Pediatria (Versão em Português), 91(1), 6-21.

Vibhute, V. M., Shelke, R. R., Chavan, S. D., \& Nage, S. P. (2011). Effect of probiotics supplementation on the performance of lactating crossbred cows. Veterinary World, 4(12), 557.

Vuong, H. E., Yano, J. M., Fung, T. C., \& Hsiao, E. Y. (2017). The microbiome and host behavior. Annual review of neuroscience, 40, 21-49.

Vuorisalo, T., Arjamaa, O., Vasemägi, A., Taavitsainen, J. P., Tourunen, A., \& Saloniemi, I. (2012). High lactose tolerance in North Europeans: a result of migration, not in situ milk consumption. Perspectives in Biology and Medicine, 55(2), 163-174.

Wai-Sun Wong, V., Wong, G. L. H., Chim, A. M. L., Chu, W. C. W., Yeung, D. K. W., Li, K. C. T., \& Chan, H. L. Y. (2015). Treatment of nonalcoholic steatohepatitis with probiotics. A proof-of-concept study. Annals of hepatology, 12(2), 256262.

Wang, H., Gao, K., Wen, K., Allen, I. C., Li, G., Zhang, W., ... \& Clark-Deener, S. (2016). Lactobacillus rhamnosus GG modulates innate signaling pathway and cytokine responses to rotavirus vaccine in intestinal mononuclear cells of gnotobiotic pigs transplanted with human gut microbiota. BMC microbiology, 16(1), 109

Wang, L., Zhang, J., Guo, Z., Kwok, L., Ma, C., Zhang, W., ... \& Zhang, H. (2014). Effect of oral consumption of probiotic Lactobacillus planatarum P-8 on fecal microbiota, SIgA, SCFAs, and TBAs of adults of different ages. Nutrition, 30(78), 776-783.

Watson, R. R., \& Preedy, V. R. (2010). Bioactive foods in promoting health: probiotics and prebiotics. Academic Press.

Watson, R. R., \& Preedy, V. R. (Eds.). (2015). Probiotics, prebiotics, and synbiotics: bioactive foods in health promotion. Academic Press.

Wells, J. M. (2011, December). Immunomodulatory mechanisms of lactobacilli. In Microbial cell factories (Vol. 10, No. 1, p. S17). BioMed Central.

Wind, R. D., Tolboom, H., Klare, I., Huys, G., \& Knol, J. (2010). Tolerance and safety of the potentially probiotic strain Lactobacillus rhamnosus PRSF-L477: a randomised, double-blind placebo-controlled trial in healthy volunteers. British 
journal of nutrition, 104(12), 1806-1816.

Xu, M., Wang, J., Wang, N., Sun, F., Wang, L., \& Liu, X. H. (2015). The efficacy and safety of the probiotic bacterium Lactobacillus reuteri DSM 17938 for infantile colic: a meta-analysis of randomized controlled trials. PloS one, 10(10), e0141445.

Yang, I., Corwin, E. J., Brennan, P. A., Jordan, S., Murphy, J. R., \& Dunlop, A. (2016). The infant microbiome: implications for infant health and neurocognitive development. Nursing research, 65(1), 76.

Yang, Y., Tian, J., \& Yang, B. (2018). Targeting gut microbiome: A novel and potential therapy for autism. Life sciences, 194, 111-119.

Yousefi, M., Movassaghpour, A. A., Shamsasenjan, K., Ghalamfarsa, G., Sadreddini, S., Jadidi-Niaragh, F., \& Hojjat-Farsangi, M. (2015). The skewed balance between Tregs and Th17 in chronic lymphocytic leukemia. Future Oncology, 11(10), 1567-1582.

Yuan, F., Ni, H., Asche, C. V., Kim, M., Walayat, S., \& Ren, J. (2017). Efficacy of Bifidobacterium infantis 35624 in patients with irritable bowel syndrome: a meta-analysis. Current medical research and opinion, 33(7), 1191-1197.

Zhang, M. M., Cheng, J. Q., Lu, Y. R., Yi, Z. H., Yang, P., \& Wu, X. T. (2010). Use of pre-, pro-and synbiotics in patients with acute pancreatitis: a metaanalysis. World Journal of Gastroenterology: WJG, 16(31), 3970.

Zhang, W., Zhu, Y. H., Yang, J. C., Yang, G. Y., Zhou, D., \& Wang, J. F. (2015). A selected Lactobacillus rhamnosus strain promotes EGFR-independent Akt activation in an enterotoxigenic Escherichia coli K88-infected IPEC-J2 cell model. PloS one, 10(4), e0125717. 